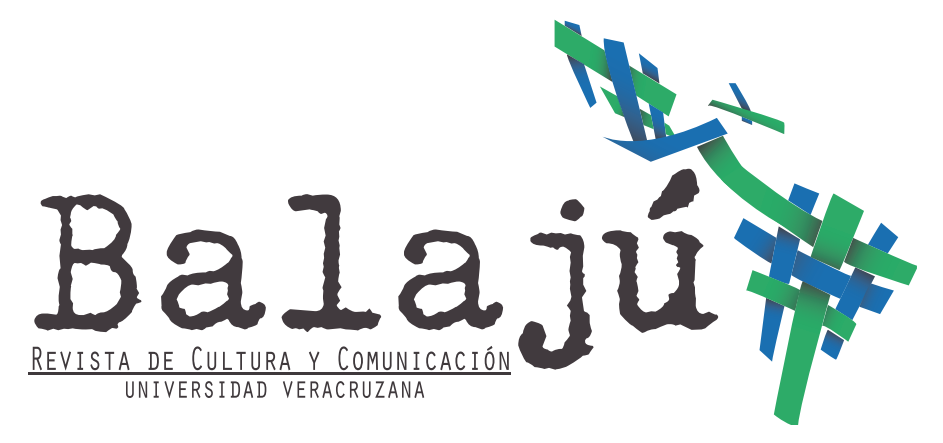

ISSN 2448-4954

No. 1, Año 1

Agosto-Diciembre 2014

\title{
La pérdida de una hija: Género y matrimonio en un contexto de migración internacional
}

\author{
María Soledad de León Torres* \\ Universidad Veracruzana, México \\ soldeleon@gmail.com
}

*Doctora en Antropología Social. Profesora-investigadora de tiempo completo en el Centro de Estudios de la Cultura y la Comunicación, Universidad Veracruzana.

\section{RESUMEN}

Este trabajo presenta las tensiones familiares que precedieron el casamiento de una mujer migrante en una entidad rural mexicana. Con base en documentación etnográfica, se muestran las contradictorias valoraciones de las mujeres y del deber ser femenino. Sugiero que los valores asociados a una ideología católica tradicional, como la virginidad y la reputación femenina basada en el control de la sexualidad, se encuentran complejamente entrelazados con una ética de consumo y con expectativas de acumulación material en la que se encuentran crecientemente involucradas las poblaciones mexicanas que participan en circuitos de migración internacional.

\begin{abstract}
This paper presents the family tensions that preceded the wedding of a migrant women in a rural Mexican entity. On the basis of ethnographic documentation, shows the contradictory assessments of women and of duty be feminine. I suggest that the values associated with a traditional catholic ideology, as the virginity and the reputation-based female in the control of sexuality, are intricately intertwined with an ethic of consumption and with expectations of material accumulation in which are increasingly involved the mexican populations involved in circuits of international migration.
\end{abstract}

\section{PALABRAS CLAVE / KEYWORDS}

Género, matrimonio, migración.

Gender, marriage, migration. 


\section{La pérdida de una hija: Género y matrimonio en un contexto de migración internacional \\ Por María Soledad de León Torres}

\section{Presentación}

El objetivo central de este artículo es ofrecer una ruta que permita explicar las diversas contradicciones y tensiones que emergieron en una localidad del occidente de México con motivo del casamiento de una mujer originaria de dicha población. La proximidad de la boda de Jovita, evento etnográficamente registrado en el estado de Michoacán, hizo visibles algunas de las tensiones culturales en las que se encuentra inmersa la población mexicana que participa en circuitos de migración internacional. La hipótesis que orienta esta revisión es que hay una relación estrecha entre el duelo expresado por los familiares de la novia y la creciente participación económica que las mujeres de esa localidad han ido ganando gracias a su inserción en los circuitos de migración internacional. Desde la perspectiva que propongo, los valores ideológicos tradicionales que se otorgan a las mujeres en la localidad se entrelazan y se mimetizan de forma conflictiva (pero eficaz) con los valores de consumo que privan en el capitalismo avanzando. Partiendo de estas premisas y apoyándome en la revisión de modelos teóricos que han examinado el trasfondo económico de valores culturales relacionados con las mujeres, veremos que el peculiar acontecimiento relacionado con la boda de Jovita requiere una mirada que trascienda los límites locales y que considere también el papel que las mujeres desempeñan en el contexto actual de la globalización y de las múltiples transformaciones provocadas por los sostenidos movimientos de población de México hacia Estados Unidos.

\section{El casamiento de Jovita y la ausencia de su familia ${ }^{1}$}

A pesar de vivir a unos cuantos kilómetros del lugar donde Jovita se casó por la iglesia, la mayor parte de la numerosa familia de esta mujer no asistió a la ceremonia religiosa ni tampoco al baile que la familia del novio organizó para celebrar el casamiento. Sólo dos de sus hermanas solteras y el mayor de sus hermanos (que fue el encargado de "entregarla" en la iglesia) participaron en la fiesta con la que se marcó el inicio esa nueva etapa en su vida. La ausencia de los padres y la parentela extensa de Jovita el día de su boda fue la expresión culminante de una atmósfera de duelo y pesadumbre que prevaleció entre su familia de origen, justamen-

1.- Como es común en los trabajos que se apoyan en datos etnográficos, los nombres verídicos de las personas aquí referidas han sido cambiados. La localidad en la que se desarrolló la etnografía es parte del municipio de La Piedad, Michoacán. 
te desde el mismo día en que los parientes de su novio fueron a "pedirla" formalmente para casarse con Ramón. Esta pesadumbre familiar, contrastó notablemente con la algarabía y la expectativa que las madrinas, las vecinas y algunas amigas jóvenes de Jovita expresaron respecto a la boda desde que la noticia de su casamiento se difundió entre esas mujeres cercanas a la novia. Jovita había logrado algo difícil de conseguir en su localidad: salir de su casa con una reputación sexual intacta y siguiendo al pie de la letra los ideales relacionados con el modelo matrimonial de su pueblo, a pesar de que en los últimos años tuvo una intensa participación en los circuitos de migración de México a Estados Unidos. Así que unos minutos antes de que iniciara la misa de casamiento en el pueblo vecino, las jóvenes vecinas de Jovita se arremolinaron para "verla salir vestida de blanco" de la casa de sus padres, mientras ellos se recluyeron en su casa y no la acompañaron ni siquiera a la puerta para despedirla del que fue su hogar durante más de treinta años.

¿Cómo puede explicarse el comportamiento de los padres de Jovita ante su boda si tomamos en cuenta que esto ocurrió en un lugar donde se sobrevalora el papel de las madres, el comportamiento sexual "recatado" de las mujeres y el matrimonio que se ha logrado "por el buen camino"? ¿Qué relaciones y fenómenos sociales pueden descifrar las actitudes de los familiares de Jovita ante su boda? ¿Qué clase de vínculos existen en la localidad de Jovita entre las mujeres y sus familias que ayuden a explicar el duelo familiar ante la boda de una mujer?

Estas preguntas ameritan hacer una revisión de los estudios realizados acerca de las valoraciones culturales en torno a lo femenino y lo masculino, así como una reflexión acerca de las consecuencias sociales de estas valoraciones. Algunos de estos estudios se han desarrollado bajo una perspectiva de género y/o feminista; pero las aportaciones a este debate también se han desarrollado en otros campos de estudio. La historia y la antropología social clásica, por ejemplo, han realizado indagaciones en torno al matrimonio y los sistemas de parentesco que han contribuido notablemente a debates fundamentales para la crítica feminista, tales como el problema del estatus que las mujeres ocupan en las sociedades y las valoraciones diferenciales de las actividades relacionadas con hombres y mujeres. En el siguiente apartado, recupero los aspectos centrales de algunos de los trabajos pertinentes para los objetivos de este artículo.

\section{La valoración de las mujeres: Intersecciones entre economía y cultura}

Para atender el problema que nos ocupa, dos ejes de reflexión estrechamente relacionados son las valoraciones de lo femenino y las diversas 
lecturas acerca del modo como el matrimonio afecta el papel y/o el estatus social de las mujeres. Una aproximación bastante prolífica en torno a estos asuntos identifica a la economía como el elemento determinante que subyace a diversos arreglos sociales y que, en consecuencia, permite explicar la elaboración cultural de los símbolos relacionados con el género social. Según esta lectura, lo femenino y lo masculino, así como el conjunto de valoraciones culturales relacionados con ambos coadyuva, a la implementación de intereses y proyectos económicos de distintas dimensiones (estructurales, familiares, personales). Estas visiones, aunque han sido desarrolladas para el análisis de sociedades diversas en el tiempo y en el espacio, son importantes porque, aunque realizadas con distintas inspiraciones ideológicas, comparten la premisa ya señalada: la idea de que lo económico subyace a (y predomina por encima de) diversos ordenamientos sociales y culturales.

Por lo que concierne a la antropología social es obligado referir a los estudios sobre sociedades mediterráneas (Pitt-Rivers, 1968; Peristiany, 1968; Davis, 1973). Estos trabajos han constituido una gran aportación para el debate sobre la valoración de lo femenino. En ellos se proponen la existencia de un complejo ideológico constituido por la dualidad honor / vergüenza que interviene de forma compleja en las relaciones sociales. El honor y la vergüenza constituyen los valores polarizados dentro de un sistema ideológico que opera en las relaciones cara a cara de cualquier sociedad: Ser merecedor del reconocimiento social o bien, por el contrario, no obtener el derecho a este reconocimiento, implica estar inserto en una jerarquía o un determinado modo de diferenciación social. Para los estudiosos de las sociedades mediterráneas, el honor es una forma de diferenciación social que se desarrolla paralelamente a la diferenciación económica. En lo que concierne al matrimonio, existe una relación estrecha entre honor, riqueza y control sexual: Las familias poderosas deben controlar la sexualidad de sus hijas pues el contacto entre personas de diferentes estratos atenta contra la concentración de bienes económicos y la estratificación social ya que se traduce en el nacimiento de hijos y una descendencia que disgrega al linaje. Para estos autores, esta es lógica económica que subyace a la elaboración simbólica de la "pureza" o "virtud" que se atribuye a la virginidad de las mujeres de la familia. La mancha o contaminación que conlleva la pérdida de la virginidad se hace extensiva a los hombres de la familia que, siguiendo este modelo de interpretación, son los depositarios de los bienes económicos y guardianes del honor familiar (Pitt-Rivers, op.cit.).

De este modo, el honor está estrechamente relacionada con diferencias materiales, riqueza y poder económico (ver síntesis en Davis, 
1973). El honor es, en pocas palabras: "Un lenguaje que expresa diferencias de riqueza" (Davis, op.cit.). Las posibilidades (o la "necesidad") de detentar o "conservar" honor, así como los riesgos a los que se expone el individuo cuando son valoradas sus conductas (como las sexuales), se derivan a final de cuentas, de la posición económica (concentración de bienes económicos) de la persona o la familia en cuestión.

Otra referencia central en esta línea de análisis es el trabajo del historiador Jack Goody (citado en Bossen 1988-89 y en Schlegel, 1991). Al discutir la interrelación que existe entre determinadas formas de cultivo, formas de matrimonio y formas de acceso a los recursos económicos, este autor propone que la riqueza de la novia y la dote están ligadas a sistemas de transmisión de la propiedad que están, a su vez, vinculados con sistemas de producción agrícola intensiva. La alta producción, la especialización, la escasez de tierra y la diferenciación de los patrimonios están ligadas a la búsqueda de mantenimiento de estatus, a la transmisión de un patrimonio o a la designación de un sucesor (Goody, 1976; citado en Narotzky, 1995). En afinidad con lo propuesto por los estudiosos de las sociedades mediterráneas, este autor sugiere que mientras las sociedades son más estratificadas, la gente tenderá a evitar los vínculos matrimoniales con familias económicamente inferiores ya que estas uniones conyugales pueden dispersar el escaso capital (la tierra). En esta clase de sociedades, las familias practican la herencia bilateral; tanto los hijos como las hijas comparten la propiedad familiar, de manera que pueden casarse con personas del mismo estatus y combinar su riqueza con la de otras personas o familias. Estos elementos, propone el autor, dan lugar a "sistemas matrimoniales cerrados"; es decir, a sistemas matrimoniales en los cuáles las uniones conyugales se llevan a cabo entre "seres semejantes" (afines en términos de una posición económica).

Tenemos así otro análisis del matrimonio que sugiere que la conservación de una determinada posición económica está detrás de las diversas reglas matrimoniales que se pueden observar en una determinada sociedad. La cuidadosa documentación etnográfica e histórica que ha sustentado estas interpretaciones en torno al matrimonio, han inspirado el cuestionamiento de varias autoras feministas. Ellas han señalado que, dados los arreglos económicos que subyacen a las transacciones matrimoniales, la formación de nuevas familias implica la subordinación, subvaloración y formas de control de "lo femenino" que, simultáneamente, exaltan y sobrevaloran y legitiman la autoridad de "lo masculino". En el tenor de esta discusión Schlegel (1991) profundiza en el papel que la virginidad femenina desempeña en las transacciones matrimoniales de sociedades preindustriales. Tomando en cuenta que las relaciones sexua- 
les premaritales también son censuradas en sociedades que proveen a las mujeres de una dote o bien en el caso de las familias que establecen intercambios económicos en términos más o menos equitativos, la autora discute la idea aceptada en otros trabajos de que "el pago de la novia" (que corre a cargo del novio o la familia del novio) constituye una retribución por las novias vírgenes. Ella aporta elementos para entender en qué radica el valor inherente que se atribuye a la virginidad, dado que también existen familias que "pagan" por dar, y no por recibir una mujer virgen. La autora llega a la conclusión de que la virginidad es prescrita y valorada en sociedades donde la dote o la herencia anticipada para las mujeres es practicada, debido a que los hombres jóvenes buscan mejorar sus condiciones de vida, relacionándose a través del vínculo matrimonial con una familia más poderosa o con una mejor posición económica. La virginidad de las mujeres jóvenes, afirma Schlegel, protege los intereses de las familias de las novias cuando éstas usan las alianzas maritales para mantener o mejorar "su estatus social". Así, apoyándose en las ideas de Goody, Schlegel confirma el argumento de que el control de la sexualidad femenina (y por ende la virginidad $u$ otra clase de conductas pre o posmaritales que pueden entenderse coherentes con esta lógica) tiene como explicación principal el propósito de evitar matrimonios "inconvenientes” que atenten contra la concentración de dinero y riqueza económica.

Siguiendo con los cuestionamientos feministas del matrimonio y la valoración de lo femenino debemos referir al trabajo de Gayle Rubin $(\mathrm{Ru}-$ bin, 1986 ). Ella elaboró uno de los argumentos más sólidos y originales que se han formulado desde el feminismo para criticar los supuestos subyacentes a las teorías clásicas de la antropología y el psicoanálisis. Cuestionando la consabida idea de Lévi-Strauss de que "el matrimonio es una forma básica de intercambio de regalos donde las mujeres constituyen el más precioso de los regalos" (Rubin, 1986; pag. 109) ella sugiere entender el intercambio de mujeres como parte de una "economía política del sexo”. Rubin pone un gran énfasis en el hecho de que las transacciones matrimoniales, en las cuales los hombres deciden sobre el "intercambio de mujeres" y estos resultan los únicos beneficiados, son sobretodo una forma de acumular riqueza y de definir el acceso diferencial a recursos políticos y económicos. Las mujeres son "oprimidas" porque no pueden "darse" a sí mismas, ya que esta es una decisión que depende de los hombres (op.cit. pag. 111). Rubin propone que el parentesco y el matrimonio forman parte de "sistemas sociales totales" en los cuales las mujeres invariablemente ocuparán una posición secundaria y subordinada. Pero esta subordinación, no es fortuita ni volitiva; siempre está ligada a ordenamientos económicos y políticos de mayor envergadura. En su análisis 
del matrimonio y la posición de las mujeres en los sistemas de parentesco, Rubin acuña la noción de "sistema de sexo/género". Ella sostiene que la "exaltación de las diferencias naturales entre los sexos" tiene como fin "imponer" una identidad de género y una sexualidad oficial (Rubin, pag. 97). El sistema de sexo/género "oprime a todos en su insistencia en una división rígida de la personalidad" (pag.115). Mediante el matrimonio y la división del trabajo por sexos (en la que el trabajo doméstico no asalariado desempeñado por las mujeres es fundamental para la extracción de plusvalía) se hace posible la "reproducción de un modo de producción", esto es, del capitalismo.

Resumiendo lo revisado en este apartado, hay que enfatizar los puntos de convergencia entre estas diversas posturas. Todas ellas proponen que el estudio del matrimonio es fundamental para abordar los papeles sociales otorgados a las mujeres y, en consecuencia, para examinar cómo se construyen las valoraciones culturales de "lo femenino". La antropología social, los estudios de género y los estudios feministas muestran que cualquier arreglo social relacionado con el matrimonio y el parentesco tiene un impacto notorio en la forma de valorar a las mujeres. Implícitamente, estos autores convergen también en la idea de que esta valoración de lo femenino, tiende a ser subordinada por la hipervaloración de lo masculino en distintas esferas de la sociedad (Rubin, 1986). De este modo, las elaboraciones simbólicas (llámese también ideología, identidades u otros conceptos relacionados) constituyen una herramienta indispensable para la legitimación de arreglos e intereses que se desarrollan en la esfera social y económica. Estas visiones teóricas en conjunto, nos ofrecen un marco apropiado para el análisis del caso etnográfico en cuestión.

\section{El ideal matrimonial en la localidad}

Poco antes de terminar el trabajo de campo que realicé en diversas localidades del municipio de La Piedad, Michoacán, fui invitada a ser una de las veinte madrinas que acompañarían a Jovita en su boda. Durante los días previos a este evento descubrí aspectos asombrosos y reveladores acerca de la sociedad en la que me había introducido meses atrás. Los preparativos de esa boda me mostraron elementos de los procedimientos matrimoniales que no habían aparecido en los relatos de las viejas abuelas del pueblo ni en las entrevistas que había hecho a los ancianos.

Según tales narrativas el modelo matrimonial se conforma de tres momentos o requisitos centrales: 1) la "petición" de la novia, 2) la fijación del "plazo" para el matrimonio, en los casos en que los padres aceptan "dar" a su hija en matrimonio y, 3) el "depósito"; esto es, el periodo 
previo al matrimonio en el cual la novia permanece recluida en casa de sus padrinos de bautizo o de algún familiar reconocido por su autoridad moral, "una persona de respeto". Según lo describieron las mismas narrativas, las parejas que siguen este camino para iniciar la vida marital suelen celebrar su unión de manera ostentosa: La familia del novio, hace la inversión que está en sus posibilidades para hacer de la boda un evento suntuoso, espléndido y públicamente visible. La contraparte de ese modelo que hombres y mujeres identifican como otras alternativas "menos deseables" (pero viables) para iniciar la vida conyugal son la "fuga" o el "rapto". Estas dos alternativas, refieren a parejas que en lugar de solicitar permiso a los papás de la novia para casarse, inician la vida conyugal representando un rapto o bien, mediante el abandono de la casa familiar emprendido por la mujer junto con su novio. En estos dos casos, se supone que sobreviene la solicitud de "perdón", que permite a los novios reconciliarse con sus padres. A diferencia del matrimonio que se obtiene por "el buen camino", en estos otros casos la celebración de la boda se restringe a los círculos familiares y es realizada de manera discreta, sin gastos excesivos ni despilfarro.

Según las propias narrativas locales de las cuáles extraje la ideología relacionada con el matrimonio, se espera que las mujeres expresen "el respeto que tienen por sus padres" durante todo el noviazgo, a partir de la petición de la novia e incluso, una vez que una mujer se ha casado y ha formado su propia familia. Gran parte de las manifestaciones de ese "respeto" están relacionadas con la evitación del contacto físico entre los novios; dicho de otro modo, con el control que las mujeres deben tener de la sexualidad. Así, para evitar el riesgo de contravenir la norma local y caer en una posición poco honorable, las mujeres solteras deben evitar encontrarse a solas, en espacios oscuros y alejados con sus novios, incluso aún cuando ya están formalmente comprometidas en matrimonio (este comportamiento se identifica como "recogimiento" o "ser recogidas").

Así pues, la exigencia a las mujeres de quedar a salvo de cualquier contacto sexual premarital se intensifica incluso una vez que la fecha del matrimonio ha sido anunciada; una vez que ya se ha realizado la "petición" formalmente y cuando el "plazo" para corroborar el compromiso se ha establecido también. Las mujeres "ya pedidas" deben evitar los espacios públicos antes del día de la boda pues lo contrario suele ser interpretado como una "falta de respeto" al futuro esposo y da lugar a comentarios suspicaces: Una mujer que fue pedida "no puede andar exhibiéndose en la calle, como si anduviera buscando marido", se dice en la localidad.

En el tiempo en que se llevó a cabo la petición de mano de Jovita también ocurrió que los temas relacionados con la sexualidad estaban 
presentes, de formas muy distintas, en los discursos femeninos. En las conversaciones con las mujeres más jóvenes (14-20 años), se debatía la relación existente entre el "pecado", el "demonio" y las relaciones sexuales prematrimoniales. Las madres de las mujeres jóvenes (30-50 años), desbordadas por las demandas de "libertad" de sus hijas para el noviazgo y para ir a los bailes y fiestas nocturnas, solicitaban a sus esposos ausentes criterios específicos para normar los espacios y los horarios a los que debían tener acceso las jóvenes. Las abuelas de esas mujeres (60 años y más) por su parte, expresaban constantemente la nostalgia que tenían por el pasado más ordenado y "respetuoso" en el que ellas mismas habían vivido sus noviazgos: Se habían "casado bien" (con el permiso de sus padres) y habían "salido de blanco" (ícono de la virginidad) de la casa de sus padres.

Otro aspecto frecuentemente expresado por las mujeres jóvenes era la falta de muchachos en el pueblo para noviar y para "escoger" un futuro esposo. Sus preocupaciones eran comprensibles debido a la evidente ausencia de muchachos jóvenes y solteros en el pueblo. El desequilibrio en las expectativas matrimoniales se explicaba también debido al incremento de los hombres jóvenes que, una vez ubicados en una localidad norteamericana, se casaban con vecinas del mismo lugar, cancelando entonces los compromisos o relaciones de noviazgo que habían establecido con alguna mujer de su lugar de origen. Era común, de ese modo, que las jóvenes solteras expresaran desilusión al ver reducidas o canceladas sus expectativas matrimoniales y de vida futura: "conseguir" un marido en esas condiciones, era una misión cada vez más complicada y frustrante para las mujeres que permanecían en el pueblo. En este contexto fue que Jovita, se sacó la lotería matrimonial...o al menos, eso me pareció al principio.

\section{Petición y duelo: Saliendo del top secret}

Luego de una trayectoria de varios años en el circuito de migración México-Estados Unidos y de las "decepciones" que había sufrido por la ruptura de varios noviazgos, Jovita no regresó más a trabajar a los campos de cultivo de California donde había estado empleada durante varias temporadas. Esta mujer canceló su vida laboral en Estados Unidos, cuando fue "pedida" en matrimonio. Antes de casarse, Jovita fue conocida en su pueblo como "una muchacha honesta" que siempre había "respetado" a sus padres; incluso a pesar de haber pasado largos periodos de su vida fuera de su localidad de origen mientras estuvo trabajando en California.

Jovita y Ramón decidieron casarse luego de varios años de que ambos alternaron periodos de residencia en Estados Unidos y en México. 
Durante tres años, el noviazgo de esta pareja se había llevado a cabo "de manera discreta", es decir, sin el conocimiento explícito de los padres o los hermanos de la muchacha, contando únicamente con la complicidad de sus hermanas solteras (que entonces, igual que Jovita, tenían alrededor de treinta años). Conforme se aproximaba la fecha que Jovita había acordado con Ramón para formalizar "la petición" ante sus padres, su inquietud iba en aumento: Todavía un día antes de la petición, Jovita no se había atrevido a confiar a nadie de su familia que ella y su novio habían decidido casarse, y que la familia de Ramón visitaría pronto a los padres de la muchacha para "pedirla" en matrimonio.

El mismo día de la petición Jovita se enteró de que su padre estaría fuera de casa a la hora que ella había acordado con Ramón para que fuera a pedir su mano. La ineludible necesidad de comunicarles a sus padres los planes matrimoniales ante la llegada inminente de la familia del novio, generó una serie de "dramatizaciones" entre las mujeres de la casa, que se expresaron de diversos modos hasta el mismo día de la boda. Preocupada por la posibilidad de que la familia de Ramón llegara cuando su padre estuviera ausente y temerosa de informar a sus padres de la importancia de su presencia ese día, Jovita activó entonces una particular cadena comunicativa a través de la cual consiguió que su padre estuviera presente en el momento en que la familia de Ramón fue a "pedirla".

El día convenido para la petición Jovita fue a buscar a una de sus cuñadas (una mujer madura y amable que la había acogido en su casa de California) para pedirle que fuera ella quien le dijera a su padre los planes para "la petición" y para que le pidiera también que regresara a casa a tiempo para esperar a los familiares del novio. La cuñada de Jovita aparentó estar "sorprendida" por la decisión de la mujer, aunque en realidad, como ella misma me dijo, ya conocía la relación de la pareja. Le dijo a Jovita que ella no era la persona adecuada para informar a su suegro de la visita de la familia de Ramón esa tarde, pero le ofreció a cambio, explicarle la situación a María, la mayor de las hermanas de Jovita, (que era soltera y vivía con sus padres también). La cuñada de Jovita trató de delegar en María el anuncio a los padres de la petición de la joven. La información, sin embargo, no fluyó con la rapidez esperada, pues Jovita y su cuñada no habían previsto el impacto que la "novedad" iba a provocarle a la hermana mayor.

María se consideraba la "segunda madre" de Jovita pues, además de la diferencia de edades que existía entre ellas, María se había hecho cargo del cuidado de todos sus hermanos durante el tiempo que sus padres se fueron a buscar fortuna a Estados Unidos. Jovita, que era la menor de la familia, se había quedado a cargo de María durante una parte de 
su niñez. De manera que, al enterarse de que Jovita "se había mandado pedir" María entró en una especie de crisis nerviosa; se deshizo en llanto. Aún en medio de la crisis, María prometió a su cuñada, que de cualquier modo se las arreglaría para que la noticia fuera comunicada al padre de Jovita y para que este estuviera en casa cuando la familia de Ramón llegara.

Mientras la noticia de la petición se iba difundiendo entre las mujeres de la casa, Jovita esperaba en la casa de su cuñada que le llevara noticias de la reacción de su padre al enterarse de la "petición". Pero a media mañana el padre de Jovita ya había salido del pueblo sin tener idea de lo que estaba pasando entre las mujeres de la casa. Mientras tanto, la cuñada y las hermanas de Jovita seguían discutiendo para decidir quién era la persona apropiada para informarle al señor sobre los planes matrimoniales de la pareja. La ausencia del padre y la larga discusión de las mujeres llevó a Jovita a su propia crisis, que entonces dijo estar arrepentida por la decisión de casarse, y de "darle esa pena" (sic) a sus padres. Finalmente, antes de la comida María, fue a decirle a Jesús (el hermano mayor de la familia) que su padre debería estar en casa al caer la tarde para recibir al novio de Jovita y su parentela. María no lo dijo explícitamente, pero asumió que Jesús tomaría la responsabilidad de hablar con su padre. Y así fue...para fortuna de Jovita que ya estaba al borde de la crisis nerviosa. A la hora de la comida, a través de su hijo mayor, el padre de Jovita se enteró de que la familia de Ramón estaría en su casa para pedir a Jovita. A diferencia de las mujeres de la casa, sin hacer comentarios ni reacciones teatrales, el padre de Jovita le indicó entonces a su esposa que debían prepararse para recibir a los parientes del novio de su hija esa tarde. Así, la madre de Jovita fue la última de la familia en "enterarse" de que la familia de Ramón iría a pedir la mano de su hija. La señora tuvo una reacción muy semejante a la de María, la hija mayor que se había hecho cargo de la crianza de Jovita. Sin embargo, tuvo que sobreponerse rápidamente a la crisis nerviosa y atender las instrucciones de su esposo para recibir a las visitas. Doña Micaela no tuvo más remedio que ordenar a sus otras hijas la preparación de varios guisos y bebidas con los que recibieron apropiadamente a la familia del novio.

Los encargados de pedir la mano de Jovita llegaron con dos horas de retraso y es fue otro motivo de estrés para todas las mujeres de la familia. Debido a que el padre de Ramón había muerto hacía unos años los responsables de hacer la "petición" fueron: uno de los hermanos del novio (ya casado), el sacerdote de la parroquia correspondiente y la madre de Ramón. Joaquín, el hermano de Ramón, se expresó "muy apenado" y "pidió disculpas" a los hermanos y al padre de Jovita por el papel que 
le había tocado desempeñar. Al pedir disculpas, como si la petición de la novia constituyera en sí misma una ofensa, Joaquín hizo un gran énfasis, en la vieja relación "de amistad y de respeto" que existía entre los hombres de ambas familias. Parecía que estaba empeñado en dirimir una posible afrenta o conflictos en ciernes.

Luego de "aceptar las disculpas" ofrecidas por los familiares del novio, el padre de Jovita y los familiares de Ramón acordaron dar dos meses de "plazo" para hacer "la presentación" (el matrimonio civil) que sería en casa de los padres del novio. Este acto, formalizó los planes matrimoniales de la pareja y dio inició a los preparativos para el matrimonio civil y religioso.

Mientras transcurrieron los dos meses de plazo acordados, la madre y las hermanas mayores se encargaron de instruir a Jovita en el trabajo doméstico para que "no fuera a quedar mal" con los parientes políticos. La hija menor de la familia, que hasta entonces se había considerado privilegiada o "consentida" tuvo que aprender a tortear, a preparar "tamales amarillos", atole y mole con pollo. Todos esos, platillos indispensables para celebrar los santos, el día de la madre, bautizos, matrimonios y demás festividades familiares y comunitarias. De este modo, Jovita permaneció en su casa la mayor parte del tiempo en el umbral de su casamiento. Sus salidas del hogar y del rancho se limitaron a las compras y preparativos necesarios para la boda (que siempre hacía en compañía de su prometido y dos o tres mujeres de las familias) la misa de los domingos y las visitas a sus amigas y parientes más cercanas. Durante ese tiempo, el hecho de que los padres estuvieran enterados del noviazgo no significó que consintieran un cortejo abierto y público. Después de la petición Ramón, el novio de Jovita, no volvió a entrar a la casa de sus futuros suegros y para "platicar" con su novia, tenían que encontrarse siempre en presencia de terceros (alguna de las hermanas) en plena la luz del día en algún punto acordado con las acompañantes de la novia.

Finalmente, el día señalado para la ceremonia religiosa, pocos minutos antes de dirigirse a la capilla, Jovita se asomó al portal de la casa donde hasta entonces había vivido con sus padres y sus hermanos. Allí, su padre la despidió con un saludo de mano, mientras su madre la miraba en silencio. La muchacha se encaminó a la puerta de la casa, y sus padres dibujaron una cruz con la mano en el aire, en señal de bendición. La madre lloró discretamente, el padre la miró y ambos se despidieron de mano. Nadie la acompañó a la puerta o al vehículo que el novio había decorado con flores y que había enviado a recogerla. Sólo Jesús, el mayor de sus hermanos (de más de cincuenta años), acompañado por su esposa, y dos de sus hermanas solteras (las más jóvenes) la siguieron en su propio ve- 
hículo hasta la capilla donde se celebró el matrimonio. En la capilla, durante la ceremonia religiosa, Jesús fue el encargado de "entregarla". Las hermanas de Jovita me explicaron la ausencia de sus padres y sus hermanos como la expresión del "respeto" que la parentela tiene a la muchacha recién casada. Esta manifestación era de conocimiento común para los otros asistentes a la fiesta pues, en el pueblo michoacano donde esa boda se realizó "no es bien visto" que los padres "festejen" la boda de su hija.

Las trágicas manifestaciones que realizaron la madre de la novia y otras mujeres de edad mayor a partir del anuncio de los planes matrimoniales de la muchacha resultaron totalmente opuestas a la forma como yo, en función de lo descrito por las narrativas, esperaba que se celebrara el matrimonio de una muchacha "honesta". Las expectativas de júbilo por el matrimonio de Jovita me parecían predecibles si tomamos en cuenta la ideología del matrimonio que he referido antes. La maternidad, la castidad femenina y el matrimonio como el mecanismo "adecuado" para emprender vida conyugal son valores exacerbados en torno a las mujeres del pueblo. Se esperaría entonces que una boda ajustada a los "procedimientos adecuados" (esto es: contando con el permiso de los padres, realizado por la iglesia sin chismes ni escándalos relacionados con la sexualidad de la novia) fuera recibida con un gran entusiasmo en su familia. Sin embargo, diversos signos opuestos a ese júbilo, surgieron a partir del día de la petición: Jovita evitaba comentar sus planes matrimoniales y cuando era interrogada sobre el tema por otras mujeres, respondía con resignación y con el asomo de un cierto sentimiento de culpa. Por otra parte, las mujeres de mayor edad que se enteraban del compromiso matrimonial expresaban su consternación y decían compartir el "dolor" de la madre y los parientes de la novia, debido a la "pérdida" que pronto iban a "sufrir".

Estas aparentes "contradicciones" en torno a la boda de Jovita, son expresiones de una ideología matrimonial que a simple vista, parece otorgar un gran valor a las mujeres. Incluso, cuando interrogué explícitamente a una mujer anciana acerca del duelo que provocaba el matrimonio de Jovita, la mujer contestó: "Cuando una muchacha se casa, es una hija que le arrancan, es como si una mujer de la familia se hubiera muerto". Pero una mirada aislada de estas manifestaciones nos daría una visión errónea y complaciente de la cultura local. Considero que para comprender la atmósfera de duelo que surge en torno al matrimonio de una hija, es muy importante tomar en cuenta el papel social que las mujeres de La Piedad están desempeñando de manera cada vez más notoria en la región. 


\section{Reflexiones para la conclusión}

Es sabido que Michoacán, junto con Jalisco, Zacatecas y Guanajuato, ha constituido antiguamente uno de los puntos de origen más importantes de los migrantes mexicanos que se dirigen a Estados Unidos. Si bien en los últimos años estos flujos se han reducido e incluso se han revertido en algunos estados debido a una suma de factores (entre los que destacan la crisis de la economía norteamericana y el recrudecimiento de las políticas migratorias en el país vecino²) México es el principal país de origen de los inmigrantes en Estados Unidos. Así se entiende también la importancia que las remesas tienen para nuestro país ${ }^{3}$.

A fines del 2012 el Banco Mundial estimó que las remesas enviadas a México sumaron alrededor de 24 mil millones de dólares, constituyéndose en la cuarta fuente de ingresos de nuestro país, luego de los recursos obtenidos por manufacturas, petróleo y turismo ${ }^{4}$. Para tener idea de la importancia que estos recursos tienen para la economía familia hay que decir que en ciertas entidades mexicanas (Guerrero, Oaxaca y Michoacán) los ingresos provenientes de remesas superan los montos producidos en la economía formal ${ }^{5}$.

La migración de México a Estados Unidos se ha caracterizado en los últimos años por una tendencia creciente a la feminización. En el año 2000 el número de mujeres migrantes a ese país alcanzó casi el medio millón, de las cuales 37,468 fueron michoacanas ${ }^{6}$. En el 2010 la Secretaría de Gobernación estimó que las mujeres representaban ya el 45 por ciento de los migrantes mexicanos que radican en Estados Unidos7. Y para el 2008 Michoacán fue la principal entidad expulsora de mujeres migrantes a los Estados Unidos. Según ese estudio de cada 100 migrantes michoacanos 36 fueron mujeres; mientras siete años atrás la proporción

2.- Fuente: Durand, Jorge (2012, 12 de agosto) “Nueva etapa migratoria” La Jornada, http://www.jornada. unam.mx/2012/08/12/opinion/022a2pol

3.- En la bibliografía hay un debate importante acerca de la "productividad" de los recursos que provienen de las remesas. Algunos autores sugieren que este dinero se despilfarra ya que se gasta principalmente en bienes de consumo o se emplea de manera suntuosa (por ejemplo en fiestas locales); las remesas son para ellos capitales ociosos o desperdiciados. Otros sugieren que estos recursos han sido fundamentales para el desarrollo de ciertas regiones de México en las cuáles el Estado se ha desentendido de la obligación de invertir en obra pública y servicios. Sin profundizar en este debate de las remesas en la macroeconomía, lo que interesa recalcar aquí es que no obstante la irregularidad de estos ingresos, las remesas tienen una gran importancia para un número considerable de familias en nuestro país.

4.- Fuente: 22 de noviembre de 2012, El Universal.

5.- Fuente: 22 de noviembre del 2012, El Universal; tomado de http://www.eluniversal.com.mx/finanzas/99039. html., consultada el 8 de enero 2013.

6.- Fuente: Cámara de diputados LX Legislatura, 2008; tomado de: http://archivos.diputados.gob.mx/Centros_Estudio/ceameg/Inv_Finales_08/DP2/2_2.pdf, consultada el 8 de enero 2013.

7.- Fuente: http://www.derechoshumanos.org.mx/modules.php?name=News\&file=article\&sid=1166, consultada el 8 de enero del 2012. 
era de 20 de cada $100^{8}$. Esto sugiere cambios importantes en el papel que las mujeres desempeñan en la economía de localidades que participan en la migración, como es el caso de La Piedad, Michoacán. Si bien ellas se han incorporado mucho más tarde que los hombres a los movimientos de población a Estados Unidos gradualmente han ido ganando un lugar cada vez más relevante en estos flujos; lo que se ha traducido en nuevas formas de generar ingresos para las familias rurales de Michoacán y también en la acentuación de ciertas formas de consumo. Este es el caso de la propia Jovita y sus hermanas, que no fueron a trabajar a ese país sino hasta que su padre y sus hermanos estuvieron bien establecidos y con una larga trayectoria laboral. Pero una vez incorporadas a estos circuitos, no dejaron de participar en ellos sino que estuvieron alternando los periodos de trabajo en Estados Unidos y los de trabajo en las actividades agrícolas de la familia en su pueblo michoacano. Sus ingresos se volvieron muy importantes para su familia de origen pues, a diferencia de los hombres que se casaron y formaron su propio hogar (lo que quiere decir, adquirieron otras responsabilidades económicas con sus propias esposas e hijos) la prolongada soltería de Jovita y sus hermanas permitió que la mayor parte de sus ingresos fueran empleadas en la construcción de todo un segundo piso de la casa de sus padres. También gracias a los recursos de las mujeres solteras migrantes de la familia se llevaron a cabo otras ampliaciones y remodelaciones constantes, la compra de muebles y artículos electrónicos que ellas consideraban indispensables para compensar los años de esfuerzo y trabajo de sus padres. La prosperidad económica de esta familia era reconocida por sus paisanos como "un ejemplo a seguir".

Vemos así una peculiar amalgama entre la exaltación de la virtud y la valoración de la pureza sexual de Jovita y sus hermanas que es vigente, se vigila y se sanciona en la localidad, y las posibilidades de acumulación económica que su familia ha logrado especialmente a través de los ingresos femeninos que se obtienen fuera de la localidad. Se observa una relación peculiar entre economía y valores culturales que influye enormemente en la vida de las mujeres (según lo han propuesto los estudios antropológicos sobre las sociedades mediterráneas) pero que aquí se presenta en su versión contemporánea, globalizada y acentuadamente mercantilizada. Los valores culturales que parecen más arraigados y esenciales, se refuncionalizan y se desarrollan a la par de valores comerciales y de consumo. Nadie en la localidad de Jovita se atreve a sugerir que las mujeres son valiosas en virtud de su papel económico, pero es evidente

8.- Fuente: 25 de abril 2008, La Jornada. Consultada en línea el 1 de diciembre del 2012 en http://www.jornada. unam.mx/2008/04/25/index.php?section=estados\&article $=037 \mathrm{n} 3 \mathrm{est}$. 
que esta participación es cada vez más importante para la economía familiar. Yo sugiero que esta es la explicación a las preguntas y aparentes contradicciones culturales expresadas en torno al matrimonio de Jovita. Debido a las contribuciones que las mujeres solteras hacen a la economía familiar, en lugar de celebrar el casamiento de una mujer que ha llegado virgen al matrimonio y demás, la familia vive este acontecimiento como un duelo: la pérdida de una hija es también la pérdida de una fuente de ingresos familiares.

\section{Bibliografía}

Bossen, Laurel (1988-89) "Toward a Theory of Marriage: The economic Anthropology of Mariage Transactions”. Ethnology, 27 (2)

Bestar, Jane F. (1999) "Marriage Transactions in Renaissance Italy and Mauss's Essay of the Gift". Past and Present. 164.

Goody, J. y E.P. Thompson (eds.) (1976) Family and Inheritance: Rural Society in Western Europe 1200-180o. Cambridge: Cambrigde University Prees.

Peristiany, J.G. (1968) El concepto de honor en la sociedad mediterránea. Barcelona: Nueva colección Labor.

Pitt-Rivers, Julian (1979) Antropología del honor o política de los sexos. Barcelona: Grijalbo

Rubin, Gayle (1986) "El tráfico de mujeres: notas sobre la `economía política’ del sexo" Nueva Antropología VIII (30) 95-145.

Schlegel, Alice (1991) "Status, property and the value of Virginity" American Ethnologist 18 (4).

Schlegel, Alice y Rohn Eloul (1988) "Marriage Transactions: Labor, Property, Status" American Anthropologist, 90. 291-309

\section{Fuentes electrónicas}

Cámara de diputados LX Legislatura, 2008; consultada el 8 de enero 2013 en http://archivos.diputados.gob.mx/Centros_Estudio/ceameg/Inv_Finales_o8/DP2/2_2.pdf ,

Durand, Jorge (2012, 12 de agosto) "Nueva etapa migratoria" La Jorna$d a$, consultado el 8 de enero 2013 en http://www.jornada.unam. $\mathrm{mx} / 2012 / \mathrm{o8} / 12 /$ opinion/o22a2pol

Martínez Elorriaga, Ernesto (2008, 24 de abril) "Michoacán, primer lugar en migración de mujeres" La Jornada, consultado el 1 de diciembre del 2012 en: http://www.jornada.unam.mx/2008/04/25/ index.php?section $=$ estados\&article $=037 n 3$ est 
"México, tercero en remesas: BM" (2012, 22 de noviembre) El Universal consultado el 8 de enero del 2013 en http://www.eluniversal.com. $\mathrm{mx} /$ finanzas/99039.html

Nerio Ana Luisa et.al. "Las mujeres mexicanas en la migración hacia los Estados Unidos: violaciones a sus derechos humanos" consultada el 8 de enero del 2013 http://www.derechoshumanos.org.mx/modules.php?name=News\&file $=$ article\&sid $=1166$, 